\title{
Math is like a lion hunting a sleeping gazelle: preservice elementary teachers' metaphors of mathematics
}

\author{
Carmen M. Latterell ${ }^{1}$ and Janelle L. Wilson ${ }^{2, *}$ \\ 1Department of Mathematics/Statistics, University of Minnesota Duluth, Duluth,USA \\ ${ }^{2, x}$ Department of Sociology/Anthropology,University of Minnesota Duluth, Duluth, USA \\ For correspondence: clattere@d.umn.edu
}

\begin{abstract}
Preservice elementary teachers hold a variety of beliefs about mathematics and mathematics learning, which influence their teaching. Previous research has shown that preservice elementary teachers believe that mathematics is doing arithmetic. However, it is unclear if preservice elementary teachers truly believe that mathematics is only arithmetic, or if they simply have a difficult time describing their views on mathematics. In this study, preservice elementary teachers were asked to provide metaphors for mathematics and mathematics learning in order to illuminate the preservice teachers' beliefs about mathematics. The metaphors were analyzed to reveal twelve different categories of belief. Approximately one-fourth of the metaphors suggested negative views about mathematics and mathematics learning. Approximately $44 \%$ of the metaphors described mathematics and mathematics learning as something that one must engage in as one travels the successes and failures of it. The metaphors prove to be a powerful tool for discovering preservice teachers' views of mathematics.
\end{abstract}

Keywords: mathematics, metaphors, preservice teachers

\section{Introduction}

Preservice elementary teachers hold a variety of beliefs about mathematics and mathematics learning, which lead to a variety of actions, once they are in charge of their own elementary school classrooms (Ernest, 1989b; Leder, Pehkonen, \& Törner, 2002). Teachers' beliefs also affect the beliefs of their students, which in some cases can lead to difficulties (Brown, McNamara, Hanley, \& Jones, 1999; Chinn, 2012; Lim, 1999a; Mtetwa \& Garofalo, 1989; Pajares, 1992; Spangler, 1992). For example, if students do not see mathematics as something useful and something that they are capable of doing, they will not put forth the required effort to learn mathematics (Schommer-Aikins, Duell, \& Hutter, 2005). In other words, "people's conceptions of mathematics shape the ways that they engage in mathematical activities" (Schoenfeld, 1989, p. 338). It might be necessary for preservice elementary teachers to explicitly examine their beliefs about the nature of mathematics before they are able to teach in a manner differently than they have been taught (Sterenberg, 2008). Elementary teachers and elementary students tend to describe mathematics as arithmetic operations and computations (Benbow, 1993; Kouba \& McDonald, 1991; Latterell \& Wilson, 2012; Seaman, J. Szydlik, S. Szydlik, \& Beam, 2005).

It is unclear if preservice elementary teachers truly believe that mathematics is only arithmetic operations and computations, or if preservice elementary teachers have a deeper view of mathematics. It is possible that metaphors may help preservice elementary teachers view their own beliefs about mathematics in a new manner. 


\section{Metaphors}

Metaphors are used to describe one thing in terms of another; perhaps something new in terms of something old. A metaphor concisely "selects, emphasizes, suppresses, and organizes features of the principal subject by implying statements about it that normally apply to the subsidiary subject" (Black, 1962, p. 44-45). Metaphors can also be used to describe something old in a new manner. That is, using a metaphor can contribute to a new understanding of an old topic (Chapman, 2002; Lakoff \& Núñez, 2000). In this way, "something new is created when a metaphor is understood" (Ortony, 1993, p. 5).

In this paper, preservice elementary teachers' metaphors are analyzed to better understand their views of mathematics and mathematics learning. "The metaphors that students use to describe their experiences of learning mathematics also show their attitudes towards mathematics" (Güner, 2012, p. 41). While creating a metaphor, a person must be active about searching for one's own meaning; that is, the very act of creating the metaphor (and not copying someone else's) demands the person to be actively involved in describing personal meaning (Ashton, 1994; Gibson, 1994; Presmeg, 1997; Selden, A. \& Selden, J., 1991).

Because humans think in metaphors, these conceptual and communication tools are essential to giving meaning to people's lives (Lakoff \& Johnson, 1980; Ortony, 1975; Schinck, Neale, Pugalee, \& Cifarelli, 2008; Sfard, 1997). Metaphors are present in everyday reasoning, as well as in abstract reasoning (Lakoff \& Núñez, 2000). "If a picture is worth 1,000 words, a metaphor is worth 1,000 pictures! ....A metaphor provides a conceptual framework for thinking about something" (Shuell, 1990, p. 102).

\section{Mathematical Beliefs and Metaphors}

Ernest (1989a) provided three views of mathematics that mathematics teachers might hold. The "problem-solving view" sees mathematics as a process and not a set of content. That is, mathematics is the process of solving problems. The "Platonist view" sees mathematics as a set of content. The "instrumentalist view" sees mathematics as useful, but a set of procedures.

Researchers have used metaphors about mathematics from secondary students, and to a smaller extent from current elementary education teachers, to understand the participants' views of mathematics. The common theme among secondary students and elementary teachers demonstrates a tendency to view mathematics negatively, but also to view mathematics as an active process, or as a structure (Cassel \& Vincent, 2011). The secondary students also tend to view mathematics as a tool, while elementary teachers view mathematics as a bridge to other things (Schinck et al., 2008).

Elementary teachers have described mathematics as a mountain to be climbed, in agreement with metaphors provided by secondary students that reflect a view that one must keep actively working at mathematics in order to succeed at it. Yet, other secondary students view mathematics as beyond one's control. Elementary teachers sometimes emphasized that the goal of mathematics is to reach the end of the problem. (Cassel \& Vincent, 2011; Gibson, 1994; Kelly \& Oldham, 1992; Noyes, 2006; Schinck et al., 2008)

The metaphors of secondary students sometimes reveal "intense feelings of anger, despair, and frustration" (Gibson, 1994, p. 8), while more positive metaphors are given when mathematics is viewed as more than just algorithms (Gibson, 1994; Schinck et al., 2008). Elementary teachers often give metaphors describing mathematics as a "battle" (Sterenberg, 2008). 
Both secondary students and elementary teachers were found to view mathematics as a structure. That is, it sets the frame for operating (Noyes, 2006; Sterenberg, 2008; Schinck et al., 2008).

A view prevalent among secondary students but not prevalent among elementary teachers is that mathematics is a tool. A view prevalent among elementary teachers but not secondary students is mathematics as a bridge. In the first view, secondary students view mathematics as something to be used in life, while in the second view elementary teachers view mathematics as connecting to future subjects and classes. (Gibson, 1994; Noyes, 2006; Schinck et al., 2008; Sterenberg, 2008)

The use of metaphors with secondary students has allowed the researchers to see "well developed and complex views about mathematics" (Schinck et al., 2008, p. 326), while using metaphors with elementary teachers has actually changed the view of elementary teachers. Sterenberg (2008) introduced four elementary teachers to the idea of mathematics as a language, which seemed to cause the teachers to consider mathematics as something humans created. That thought in turn tended to move the elementary teachers from their previous metaphors of mathematics as a static image to view mathematics as something capable of changing as it is communicated. That is, mathematics as a language makes it a process of communicating, interpreting, translating, and, possibly, changing in meaning.

Studies have also been done with adults who were not teachers. The adults who were not teachers tended to view mathematics as something that takes time, similar to the secondary students and the elementary teachers. But, the non-teacher adults also viewed mathematics as a puzzle, implying the view that mathematics is both challenging and fun. (Allen \& Shiu, 1997; Lim, 1999b).

This study will use a large sample size $(n=93)$ in order to paint a broad picture of elementary teachers' metaphors. The hypothesis is that metaphors will reveal the deeper and, as of now, unarticulated views of elementary teachers about mathematics. This work is situated in the belief that mathematics is a discourse, a communication, and mathematical ideas are "shaped by our bodily experiences" (Lakoff \& Núñez, 2000, p. xiv). In this sense, mathematics is a human, creative, interactive experience, and not a body of content, per se. Although this view certainly biases the researchers away from a definition of mathematics as numbers and number operations, the point of the study was to look at mathematics through the eyes of preservice elementary teachers via metaphors.

\section{Research Questions}

The following questions guided the study:

1. What metaphors do preservice elementary teachers use to describe mathematics?

2. What metaphors do preservice elementary teachers use to describe the learning of mathematics?

Through the lens of these metaphors, what can be said about how preservice elementary teachers view mathematics?

\section{Method}

Participants and Data Collection.In a mid-sized university in the Midwest, one of the researchers teaches an undergraduate course entitled "Mathematics for Elementary Education Majors," a required mathematics course for students majoring in elementary education which may be taken at any point in the undergraduate process. The majors take a separate course on methods for teaching mathematics. The course involved in this study is a content course in mathematics that covers topics needed to teach kindergarten through eighth-grade mathematics. The content is presented in such a manner as to encourage a deep, conceptual understanding of elementary topics. For example, when 
algorithms are presented, the emphasis is placed on why the algorithms work the way they do in our base-ten number system. In the fall of 2013, the class had an enrollment of 93 elementary education majors with 11 male students and 82 female students. Most of the students were Caucasian.

At approximately one-third of the way into the semester, the researcher passed out a piece of paper during a class meeting time. On the paper was written:

A metaphor is a figure of speech that describes one thing in terms of another."Time is a dressmaker specializing in alterations. The rain came down in long knitting needles." A simile is a type of metaphor that compares the two things through the use of words such as "like" or "as." "She is like a candy so sweet. It was as easy as pie."

The researcher also read the words out loud to the students. The researcher then asked the students to write a metaphor or simile that describes mathematics, and to write a metaphor or simile that describes what it is like to learn mathematics. The rest of the paper was blank, and they were to write their two metaphors on the paper. Of the 93 participants, 88 provided responses that constituted data to analyze (the other five participants turned in a blank paper). The students received participation points for turning in the paper.

Analysis.A metaphor has a topic (math), a target (e.g., life, puzzle, roller coaster), and the ground, with the ground describing the particular relationship between the topic and the target (Saban, Kocbeker, \& Saban, 2007). It is not the target itself that matters so much, but what is being suggested by the comparison. Thus, the eventual goal in the data analysis was to categorize each of the metaphors according to its ground. The data analysis then is "essentially a qualitative research methodology related to content analysis, but it also allows researchers to apply quantitative procedures on the categorical data, resulting from the uncovering of the meanings and reasoning beneath those consciously set forth by the participants in each metaphorical relationship" (Saban et al., 2007, p. 126).

When the analysis began, it was planned to treat the metaphors that began "Math is like" separately from the metaphors that began "Learning math is like." With each group, then, each of two researchers separately grouped the metaphors into categories according to their ground. That is, two metaphors were placed into the same group if each metaphor made the same comparison. For example, Mathematics is a long bike ride that goes on and on for a great distance, was deemed to offer the same comparison as Mathematics is a gumball, because one must chew it and chew it and chew it for a long time. A bike ride and a gumball are not the same thing, but the metaphors might be judged by the researcher as the same.

Once each researcher had placed the metaphors into categories, each researcher named the resulting categories. For example, one category was named "up and down"(that is, mathematics is a process with ups and downs) by one of the researchers, and examples of metaphors in it were "Math is like a roller coaster" and "Math is like going up and down hills". At the next step, the researchers compared category names. At this point, the researchers did not discuss which metaphors were placed into which categories, but only the names of the categories that each researcher had developed.

During discussion of the category names, it became clear that the categories were the same for each type of metaphor (i.e., those that began "Math is like" were categorized into the same categories as those that began "Learning math is like"). It was decided at this point to treat all the metaphors as one large group. 
It does not matter what each researcher named each category, if the meaning is the same. For example, each researcher did have a category that the one had named "up and down" and the other had named that category "process", meaning mathematics is a process with successes and mistakes. It took considerable discussion to understand which category names the two researchers had in common.

One of the researchers had twelve categories, and the other had ten. In the end, twelve categories were chosen, with a match on eight of the twelve eventual categories (Difficult, Easy, Language, Necessary, Pleasant, Process, Puzzle, and Unpleasant). The Unpleasant category was large, and one of the researchers had split it to include Dangerous, while the other had included Impossible. It was decided that these would be three separate categories. Also, one of the researchers had separated the Process category to include Expansive and Endless. It was agreed to include these.

The twelve categories, then, were Dangerous, Difficult, Unpleasant, Impossible, Easy, Pleasant, Endless, Expansive, Process, Language, Necessary, and Puzzle. After the categories were defined the researchers separately coded all the metaphors according to the 12 categories created. Finally, the researchers compared metaphor by metaphor to see into which category each researcher had placed each metaphor. Before the discussion, the inter-rater reliability was $75 \%$.

The researchers discussed the metaphors for which there was disagreement. The majority of the disagreements were found in the choice between Impossible and Difficult, the choice between Difficult and Unpleasant, and the choice between Process and Expansive. With further clarifications on how each was viewing these categories, and further discussion, a $100 \%$ agreement was reached. However, when the results are given, the categories of Impossible, Difficult, Unpleasant, and Dangerous will be reported together. If these had been grouped together in the first place, there would have been an initial $100 \%$ inter-rater reliability. We concluded that the label of Difficult or Impossible was less relevant to our findings than consistency of coding individual metaphors. Seven of the metaphors were categorized into two categories each. For example, the metaphor "math is like a puzzle, there is always a lost piece" was placed in the Puzzle category and the Impossible category.

\section{Results}

As noted above, the analysis of the data resulted in 12 categories. In the following, each category is presented with a description and some representative metaphors. The categories are grouped together with similar categories.

Dangerous, Difficult, Unpleasant, Impossible. Four categories contained 26\% of the metaphors. This category may represent Ernest's (1989a) instrumentalist view, in the sense that mathematics is viewed as a set of unrelated skills, which makes it difficult to master mathematics. However, Ernest mentions that mathematics is useful, while the metaphors in these four categories do not tend to convey usefulness.

Forty-seven metaphors were in this grouping and revealed a comparison of mathematics to something dangerous $(n=8)$, difficult $(n=10)$, unpleasant $(n=15)$, or impossible $(n=14)$.

According to some of the metaphors, mathematics is like something dangerous, containing an element of harm, injury, or risk:

- Math is like a tornado in Kansas.

- Math is like a lion hunting a sleeping gazelle (I'm the gazelle).

- Math is like the home of Satan, hell.

- Learning math is like walking through a field of bombs I don't want to set off. 
A number of respondents suggested metaphors that present math as a difficult subject matter to understand or master:

- Learning math is like trying to diet. I can do it for a short amount of time, but then I quickly give up.

- Learning math is like waking up early for school. It's hard to learn math and get up in the morning.

- Math is like a tangled ball of yarn, the more you try to work it out, the more complicated it gets and the more frustrated you get.

Some of the metaphors actually described things that were impossible, such as "fitting a square peg into a circular hole." Illustrative statements include:

- Math is like Atlantis, because I am lost.

- Learning math is like trying to walk on water, very difficult.

- Learning math is like trying to find a needle in a haystack.

A number of students find mathematics to be unpleasant, and write metaphors to describe sheer unpleasantness. However, the metaphors stop short of describing an impossible situation:

- Learning math is like a bad case of the flu.

- Math is like a headache.

- Math is like nails on a chalkboard.

Around one-fourth of the metaphors, then, describe mathematics in a rather negative fashion, ranging from somewhat unpleasant (e.g., a headache), to difficult (e.g., a diet), to dangerous (e.g., tornado), and, finally, to impossible (e.g., walking on water). Again, it is possible that some students find difficult things enjoyable, and dangerous things exciting. Thus, it is possible that using the term "negative" on the part of the researchers is not completely correct. But, one can still say that around one-fourth of the metaphors described mathematics as something one does and in the doing, encounters some roadblocks.

Easy, Pleasant.The categories of easy and pleasant contained metaphors that revealed a more positive approach to mathematics, but only $8 \%$ of the metaphors were contained in these two categories. A small number of students offered metaphors $(n=9)$ that suggest that they find math easy:

- Math is like breathing, comes natural to me.

- Learning math is like hitting a softball off a tee.

- Learning math is like taking candy from a child; easy.

A small number of students who simply enjoy doing mathematics gave metaphors $(n=5)$ of a pleasant nature.

- Learning math is like a warm summer breeze.

- Learning math is like taking a bike ride through a park.

- Math is like a walk through the fall leaves.

Although only $8 \%$ of the metaphors described mathematics as easy (e.g., taking candy from a child) or pleasant (e.g., walking through a park), most of these metaphors again describe mathematics and mathematics learning as something active (e.g., walking, hitting, taking).

Endless, Expansive, Process. The three categories of endless, expansive and process contained $44 \%$ of the metaphors. This category corresponds to Ernest's (1989a) problem solving view of mathematics. Mathematics is the process of solving problems, and it is ever expanding. The endless category represents that mathematics is always changing, and the expansive category captures that 
mathematics expands the participant's viewpoints. However, it is not easy at times to tell the difference in these three categories, and so they are grouped together.

The Endless category $(n=5)$ describes mathematics as something that continues throughout one's entire life. Math is viewed as continuing without end. Learning math is viewed as an ongoing process and not a finite one that could be mastered:

- Math is like the seasons. Always changing or moving around, used one second forgotten the other, but like the seasons, we always come back to them.

- Math is like a fun game of Tetris in which there is no end!

- Learning math is like a never-ending maze.

Some students described mathematics $(\mathrm{n}=12)$ as having the power to expand their world. Through mathematics, they began to understand the world in new ways:

- Math is like seeing the world through a new set of eyes.

- Math is like an unknown wonder of the world waiting to be discovered.

- Learning math is like diving into the ocean, always encountering new creatures.

A large number of students viewed mathematics as a sort of "rollercoaster" with ups and downs ( $\mathrm{n}=$ 62). It is a process that they have to enter into, and at first it is difficult, and then it gets easier:

- Learning math is like a rollercoaster.

- Learning math is like reading a book, at first, you don't know what's happening but by the end everything makes sense.

- Math is like learning a new toss in color guard, it feels good once I figure it out but it can be hard to get there.

- Math is like running. It is challenging and takes focus, but finishing is rewarding and gives a sense of pride.

The largest portion of metaphors were found in this cluster of categories, with $44 \%$ of the metaphors describing mathematics as something one must do and persevere at. Many of the metaphors referred to the struggle of mathematics, in the sense that at times it was easier than at other times. Some of the metaphors referenced a sense of accomplishment when success was reached. These metaphors describe mathematics as so much more than the working of an isolated arithmetic problem.

Puzzle. Another view of math is that it is a puzzle to be solved $(\mathrm{n}=20)$. Math is made up of problems that one has to figure out:

- Math is like putting a puzzle together.

- Math is like a million piece puzzle that you slowly put together.

- Math is like a puzzle, somehow everything goes together to form a big solution.

- Learning math is like solving a puzzle with many pieces.

The researchers considered placing the Puzzle category inside of the Process category as well. Putting a puzzle together could be described as a process. However, the Process metaphors described processes that are ongoing. The Puzzle metaphors described a process that reaches a conclusion, a product, a completed puzzle. Although this distinction might be subtle, it was viewed as important. The metaphors that used the word puzzle tended to not give much further explanation, as if it was clear what a puzzle is, and mathematics is a puzzle. That is to say, mathematics is not so much like a puzzle, it is a puzzle. Whether students enjoy puzzles (and therefore it is a pleasant experience) or do not (and perhaps it is an unpleasant experience) is beyond the researchers' knowledge. However, once again, the metaphors suggest that mathematics is not just content, but something that someone does. 
Necessary.Some students believe that the world is mathematical and that people use mathematics everyday $(n=16)$. They reference things like money, time, and temperature as everyday mathematics. Thus, math is simply necessary:

- Math is like the skeleton that holds up a body of understanding.

- Math is like a toothbrush, you use it every day.

- Math is like homework. You need it in order to be successful in your job.

- Math is like water, we need it to survive.

In these metaphors, mathematics is viewed as important (downright needed), but it is really not clear beyond that what the participants think mathematics is. Indeed, it might be that mathematics is arithmetic, and arithmetic is a needed part of the world.

Language. The final category was language and it contained 7 metaphors. In this category (as in the puzzle category) students directly use the ground.

- Math is like a universal language we all try to learn.

- Learning math is like trying to understand another language.

In these examples, the participants use the word "try" or "trying". It is possible that these metaphors are actually describing the difficult nature of mathematics. Regardless, they do view mathematics as a language, and this is a somewhat common view of mathematics among mathematics teachers. It is possible that the researcher even used this term while teaching. Since only 7 of the metaphors used it, the researchers will not attempt to take much away from this.

\section{Discussion}

The first two research questions asked what metaphors were used to describe mathematics and the learning of mathematics. The preservice elementary teachers used a variety of metaphors to describe mathematics and mathematics learning. Table 1 gives the number of responses in each category.

Table 1. Category Quantity

\begin{tabular}{lll}
\hline Category & Math is & Learning math is \\
\hline Dangerous, Difficult, Unpleasant, Impossible & 22 & 25 \\
Easy, Pleasant & 7 & 7 \\
Endless, Expansive Process & 32 & 47 \\
Puzzle & 16 & 4 \\
Necessary & 13 & 3 \\
Language & 2 & 5 \\
\hline
\end{tabular}

Participants gave metaphors that described mathematics and the learning of mathematics as something dangerous, difficult, impossible or unpleasant. A smaller number of metaphors described mathematics and the learning of mathematics as pleasant or easy. Metaphors described puzzles, and the necessary nature of mathematics. A quite small number described mathematics as a language. The largest number of metaphors described mathematics and the learning of mathematics as a process that one must enter into with resulting ups and downs in successes and failures.

The participants did not make a lot of distinctions in their metaphors for math as content versus the learning of mathematics. However, there are quite a few metaphors that described mathematics as a puzzle, while describing the learning of mathematics as a process. This pairing of the content as a puzzle to be solved through the process of learning was an interesting and common connection. 
The third research question asked how these metaphors might help reveal how preservice elementary teachers actually view mathematics. Previous research (Latterell \& Wilson, 2012; Cassel \& Vincent, 2011) suggests that elementary teachers view mathematics as nothing more than arithmetic and arithmetic operations. Actually, none of the metaphors described a view that mathematics is strictly arithmetic operations. It is possible that the participants do view mathematics as arithmetic operations, but if so, they also view mathematics as a process that one enters into.

The metaphors reveal a view of mathematics as much more than a set of content. In fact, every metaphor gives a view of mathematics as something with which the participant must engage. Although approximately one-fourth of the metaphors describe that engagement as difficult, unpleasant, impossible, or even dangerous, it does not take away from the engagement. In fact, perhaps the participant does not find such engagement (especially the dangerous category) as a negative process, but an exciting one. This is beyond the researchers' ability to know.

The strongest theme revealed from the metaphors is that mathematics is something that one must do in an ongoing fashion. Mathematics is a process and the learning of mathematics is accomplished through the process of doing mathematics. In contrast to the Cassel and Vincent (2011) study revealing an end-product view of mathematics, the participants in this study viewed mathematics as continuing without end.

\section{Conclusion}

How preservice elementary teachers view mathematics has an influence on how they will eventually teach mathematics, which in turn influences elementary students' learning of mathematics. Many preservice elementary teachers seem to define mathematics as nothing more than just arithmetic operations (Latterell \& Wilson, 2012). Is this also their view of learning mathematics? Or haven't teachers had a full opportunity to explain how they define mathematics and why?

The preservice elementary teachers in this study did reveal a more process view of mathematics. It is possible that this process view is present more than previously thought, and could be developed. That is, this study seems to suggest that when directly describing mathematics, preservice elementary teachers rely on a definition regarding arithmetic operations, but when using metaphors, they are able to express a more meaningful connection to mathematics. This study then uncovered nuances of more global categories that earlier researcher identified.

Unfortunately, also somewhat present in the participants' metaphors were negative emotions, similar to what Gibson (1994) found. Recall that Güner (2012) found more positive metaphors among secondary students who were successful in mathematics courses. Putting these results together seems to beg the conclusion that if it was possible to teach mathematics to elementary education majors in such a manner as to relieve their anxiety and negative emotions, they might be more likely to let the process view manifest. No one wants to enter a process (or encourage others to enter that process) that is viewed to be unpleasant.

Thus, one possible implication of this study is to create interesting, low-anxiety lessons in college elementary education mathematics courses that would engage these majors into the pleasant process of mathematics! Those who love the discipline of mathematics cannot always understand the negative attitudes towards the discipline. However, the respondents' metaphors demonstrate that despite the negative responses of $26 \%$ of the elementary education majors, an alternative view is also evident - a view of mathematics as a process that is worth entering. In order to break the cycle of elementary teachers passing on negative views of mathematics, it is important to examine what these metaphors reveal. 


\section{References}

Allen, B., \& Shiu, C. (1997). 'Learning mathematics is like...' -views of tutors and students beginning a distance-taught undergraduate course. British Society for Research into Learning Mathematics, 17(1). Retrieved from http://www.bsrlm.org.uk/IPs/ip17-12/BSRLM-IP-17-12-2.pdf

Ashton, E. (1994). Metaphor in context: An examination of the significance of metaphor for reflection and communication. Educational Studies, 20, 357-366.

Benbow, R. M. (1993). Tracing mathematical beliefs of preservice teachers through integrated content-methods courses. Proceedings of the Annual Conference of the American Educational Research Association. Retrieved from ERIC database. (ED388638)

Black, M. (1962). Models and metaphors: Studies in language and philosophy. Ithaca, NY: Cornell University Press.

Brown, T., McNamara, O., Hanley, U., \& Jones, L. (1999). Primary student teachers' understanding of mathematics and its teaching. British Educational Research Journal, 25, 299-322.

Cassel, D., \& Vincent, D. (2011). Metaphors reveal preservice elementary teachers' views of mathematics and science teaching. School Science and Mathematics, 111, 319-324.

Chapman, O. (2002). Belief structure and math teacher growth. In G. C Leder, E. Pehkonen, \& G. Törner (Eds.), Beliefs: A hidden variable in mathematics education? (pp. 177-193). Netherlands: Kluwer Academic Publishers.

Chinn, S. (2012). Beliefs, anxiety, and avoiding failure in mathematics. Child Development Research, (2012), 1-8. doi:10.1155/2012/396071

Ernest, P. (1989a). The knowledge, beliefs and attitudes of the mathematics teacher: A model. Journal of Education for Teaching, 15, 13-33.

Ernest, P. (1989b). The impact of beliefs on the teaching of mathematics. In P. Ernest (Ed.), Mathematics teaching: The state of the art (pp. 249-254). London: Falmer Press.

Gibson, H. (1994). Math is like a used car. In D. Buerk (Ed.), Empowering students by promoting active learning in mathematics: Teachers speak to teachers (pp. 7-12). Reston, VA: National Council of Teachers of Mathematics.

Güner, N. (2012). Using metaphor analysis to explore high school students' attitudes towards learning mathematics. Education, $133,39-48$.

Kelly, L., \& Oldham, E. (1992, August). Images of mathematics among teachers: Perceptions, beliefs, and attitudes of primary teachers and student teachers in the Republic of Ireland. Paper presented at the $7^{\text {th }}$ International Congress on Mathematical Education (ICME-7), Working Group 21: Public Images of mathematics, Quebec, Canada.

Kouba, V. L., \& McDonald, J. L. (1991). What is mathematics to children? Journal of Mathematical Behavior, 10, 105-113.

Lakoff, G., \& Johnson, M. (1980). Metaphors we live by. Chicago: The University of Chicago Press.

Lakoff, G., \& Núnez, R. E. (2000). Where mathematics comes from: How the embodied mind brings mathematics into being. New York: Basic Books.

Latterell, C. M., \& Wilson, J. L. (2012). Students' perceptions of what mathematicians do. The Mathematics Educator, 13(2), 73-84.

Leder, G., Pehkonen, E., \& Törner, G. (2002). Beliefs: A hidden variable in mathematics education? Dordrecht: Kluwer.

Lim, C. S. (1999a). Public images of mathematics. (Doctoral dissertation, University of Exeter). Retrieved from http://people.exeter.ac.uk/PErnest/pome15/lim_chap_sam.pdföö

Lim, C. S. (1999b). Using metaphor analysis to explore adults' images of mathematics. Philosophy of Mathematics Education Journal, 12. Retrieved from http://people.exeter.ac.uk/PErnest/pome12/article9.htm

Mtetwa, D., \& Garofalo, J. (1989). Beliefs about mathematics. Academic Therapy, 24, 611-618.

Noyes, A. (2006). Using metaphor in mathematics teacher preparation. Teaching and Teacher Education, 22, 898-909.

Ortony, A. (1975). Why metaphors are necessary and not just nice. Educational Theory, 25, 45-53.

Ortony, A. (1993). Metaphor, language, and thought. In A. Ortony (Ed.), Metaphor and thought (2nd edition, pp. 1-16). New York, NY: Cambridge University Press.

Pajares, M. F. (1992). Teachers' beliefs and education research: Cleaning up a messy construct. Review of Educational Research, 62, 307-332.

Presmeg, N. C. (1997). Reasoning with metaphors and metonymies in mathematical learning. In L. D. English (Ed.), Mathematics reasoning: Analogies, metaphors, and images (pp. 267-280). Mahwah, NJ: Erlbaum.

Saban, A., Kocbeker, B. N., \& Saban, A. (2007). Prospective teachers' conceptions of teaching and learning revealed through metaphor analysis. Learning and Instruction, 17, 123-139.

Schinck, A. G., Neale, H. W., Jr., Pugalee, D. K., \& Cifarelli, V. V. (2008). Using metaphors to unpack student beliefs about mathematics. School Science and Mathematics, 108, 326-333. 